\title{
Regional public goods and international organizations
}

\author{
Todd Sandler
}

Received: 11 January 2005 / Accepted: 23 March 2005

(C) Springer Science+Business Media, Inc. 2006

\begin{abstract}
This article focuses on the provision prognosis for regional public goods (RPGs) and the role of international organizations in fostering supply in developing countries. All three properties of publicness-i.e., nonrivalry of benefits, nonexcludability of nonpayers, and the aggregation technology-play a role in this prognosis. The paper highlights many provision impediments, not faced by national or global public goods. When intervention is necessary, the analysis distinguishes the role of global, regional, and other institutional arrangements (e.g., networks and publicprivate partnerships). The pros and cons of subsidiarity are addressed.
\end{abstract}

Keywords regional public goods $\cdot$ global public goods $\cdot$ subsidiarity aggregation technology $\cdot$ collective action $\cdot$ networks $\cdot$ developing countries

JEL codes $\mathrm{H} 87 \cdot \mathrm{O} 18 \cdot \mathrm{R} 58$

\section{Introduction}

Globalization is associated with increased cross-border flows that include goods, services, financial capital, and labor. Borders are also porous to pollutants, diseases, terrorism, knowledge, culture, financial crises, political upheavals, conflicts, medical breakthroughs, inventions, and computer viruses and worms. These new flows, driven by market globalization and technology, indicate that collective action, orchestrated at times by international organizations, is needed beyond the nationstate to control an expanding number of transnational public goods (TPGs). In contrast to national public goods (NPGs), TPGs provide nonrival and nonexclud-

T. Sandler (荬)

School of International Relations,

University of Southern California,

Von Kleinsmid Center 330, Los Angeles, CA 90089-0043, USA

e-mail: tsandler@usc.edu 
able benefits to people in two or more countries. ${ }^{1}$ Some TPGs provide benefit or cost spillovers globally-e.g., efforts to reduce ozone-shield-depleting chlorine and bromide substances improve the well-being of people worldwide. When spillovers are global, the associated good is a global public good (GPG). If, instead, the public good's benefits are confined to two or more countries in a given location, then the good is a regional public good (RPG), whose spillovers may be more confined than TPGs.

In recent years, there is a growing interest in the study of GPGs and TPGs beginning with Global Challenges (Sandler, 1997) and followed by other contributions (see, e.g., Ferroni and Mody, 2002; Kanbur, Sandler and Morrison, 1999; Kaul, Grunberg and Stern, 1999; Kaul, Conceição, Le Goulven, and Mendoza, 2003; Sandler, 1998, 2004). Some studies focus on RPGs and their associated collective action problems (Arce and Sandler, 2002; Cook and Sachs, 1999; Estevadeordal, Frantz and Nguyen, 2004; Sandler, 1998, 2002; Stålgren, 2000), while others analyze GPGs and their provision efforts to date. A primary concern is to distinguish TPGs for which nations have the proper incentives to contribute from those where incentives are perverse. Another concern is to identify the role of diverse agents and international organizations-i.e., global (e.g., World Bank, United Nations) institutions, regional institutions, networks, public-private partnerships, and charitable foundations - in bolstering TPG provision in developing countries. In recent years, increased foreign assistance has been channeled in a bilateral and multilateral fashion to finance TPGs in developing countries. Based on data from the Organization for Economic Cooperation and Development (OECD), te Velde, Morrissey and Hewitt (2002: 128) show that aid-funded public good support more than doubled from $16.22 \%$ of assistance in $1980-82$ to $38.19 \%$ in $1996-98 .^{2}$ Much of this increase was in terms of NPGs: in 1996-98, 29.40\% of official assistance funded NPGs compared with 8.79\% for TPGs (te Velde et al., 2002: 126-127).

The current study has two essential purposes: to survey the current knowledge of RPGs and to push this knowledge frontier outward. In accomplishing the first goal, the modern study of public goods and collective action (Olson, 1965; Sandler, 1992, 2004) is applied to assess the effectiveness of the support for RPGs in developing countries. All three properties of publicness-nonrivalry of benefits, nonexcludability of nonpayers, and the aggregation technology (i.e., how individual contributions add to the overall level for consumption) - indicate where to direct efforts in providing RPGs. Blanket statements about RPGs must be resisted since these goods display a wide range of publicness properties and prognoses. Once the prognosis is understood, the role of national and international institutions in promoting the supply of RPGs and GPGs in developing countries will be known.

\footnotetext{
${ }^{1}$ Benefits are nonrival when a unit of the good can be consumed by one agent without detracting, in the least, from the consumption possibilities still available for other agents from the same unit. Benefits are nonexcludable when they are available to all would-be consumers once the good is supplied.

${ }^{2}$ Estimates by Raffer (1999) indicate that support for public goods varied from $20 \%$ to $40 \%$ of official development assistance in the 1990s, depending on the classification of public goods used. The growth of aid-supported public goods is further documented in a recent study by Mascarenhas and Sandler (2005). Also see the World Bank (2001) study, which distinguishes between complementary and core activities. Complementary activities lay the infrastructure for developing countries to consume TPGs - the so-called core activity. The former require NPGs that prepare the country to benefit from TPGs.
}

照 Springer 
For the second goal, we highlight the importance of the aggregation technology. The unique position of RPGs vis-á-vis NPGs and GPGs is clarified for the first time. Moreover, the article identifies the role of global and regional institutions in fostering the provision of RPGs in developing countries. The article also highlights the pros and cons of applying the principle of subsidiarity to the choice of jurisdiction and international organizations. Finally, the article explores new institutional arrangements and participants-i.e., networks, public-private partnerships, regional trade pacts, and nongovernmental organizations (NGOs) - to augment RPG provision where needed.

\section{RPGs: A Typology and Implications}

This section explores the properties and classes of RPGs in regards to developing countries in order to identify the need for international organizations to bolster the provision of RPGs. In many instances, intervention may not be needed, but, when required, the form of intervention and the requisite institutional arrangement hinge on the publicness properties of the RPGs. Hence, this taking stock of RPGs is essential. An RPG provides benefits to two or more nations in a well-defined region. A region is a territorial subsystem of the global system, whose basis may be geological (based on earth formations such as a plain or coastline), geographical, political, cultural, or geoclimatic. Regional characteristics can influence the extent of spillovers from a public good-e.g., language can facilitate or limit spillovers, while natural barriers, such as mountain ranges, may also affect the range of spillovers. Because agricultural research findings are specific to soil and climatic conditions, geoclimatic factors can be the prime determinant of the range of the resulting spillovers. Thus, knowledge public goods can be regional in nature. Diseases and pests may be indigenous to some regions so that defensive measures may yield RPGs.

The two classic properties of a pure public good give rise to market failures that may require either government provision or some form of cooperation among the benefit recipients. Nonexclusion results in a market failure because a provider cannot keep noncontributors from consuming the good's benefit. Once the public good is provided, consumers have no incentive to contribute because their money can purchase other goods whose benefits are not freely available. Thus, the public good will be either undersupplied or not supplied. Benefit nonrivalry means that extending consumption to additional users results in a zero marginal cost. Exclusionbased fees are inefficient because some potential users, who derive a positive gain, are denied access even though it costs society nothing to include them. Purely public RPGs include cleansing a local ecosystem, curbing the spread of an infectious disease, curing a region-specific disease, and instituting regional flood control.

\subsection{Purely Public Versus Impurely Public RPGs}

For purely public RPGs, intervention by a global institution, regional organization, or other collective is required for provision. Impurely public RPGs may, at times, have a more favorable prognosis. Impurity can stem from partial rivalry or partial excludability. Suppose that impurity is due to partial rivalry alone. An example is a 
common property resource, such as a regional fishing ground, where access is open to all nations in the region. Rivalry applies because increased fishing effort by one nation limits the catch of other nations through crowding. To haul in the same catch, each nation's fleet must exert more effort as that of other nations increases. This problem can be addressed if a regional body restricts fishing efforts to account for the crowding externality. Nations are not anticipated to reduce overexploitation on their own unless there is a nation with a sufficiently large stake in the fishery and/or the ability to impose restrictions on others.

Next, suppose that an RPG is impure owing to partial rivalry and partial excludability. Partial rivalry means that extending consumption has a nonzero marginal cost owing to crowding (e.g., treating diseased patients, monitoring a disease outbreak, or cleaning up an oil spill), so that a crowding toll can be levied without necessarily implying inefficiency. The partial exclusion indicates that some of the users can be denied entry unless they pay the toll. The lack of complete excludability means that there will still be some free riders who will use the good, crowd others, and escape payment. Thus, the good will be undersupplied and overutilized, which worsens as the degree of exclusion decreases.

\subsection{Club Goods}

Club goods are impure public goods whose benefits are fully excludable and partially rival. Club RPGs include regional parks, power networks (e.g., Central American Electricity Interconnection System (SIEPAC)), ${ }^{3}$ transportation infrastructure, crisis-management teams, satellite-launch facility, and biohazard facility. Members can efficiently provide these club RPGs, financed through tolls. If exclusion is complete, then there will be no free riders and only members benefit. The toll charges each user the same fee, which equals the crowding costs associated with a standardized unit of use or visit. Taste differences among members can be taken into account: members with a stronger preference for the club good will use it more frequently and will thus pay more in aggregate tolls. Under a wide range of scenarios, the tolls collected will finance the efficient level of provision (Cornes and Sandler, 1996).

Suppose that nations in a region jointly utilize a satellite-launch facility (e.g., Alcântara in Brazil for Latin America). Each launch is charged the same fee, but countries that launch more satellites will pay more in total charges. Such a club arrangement means that resources will gravitate to their most-valued use without the need for outside intervention. Regional clubs can seek loans from global institutions, donor nations, or regional development banks to initially finance the club good. Toll proceeds can subsequently repay the loan. Members can be quite heterogeneous and include nations, private firms, and other organizations. INTELSAT is a global club that is a private consortium with diverse members that share a satellite-based communication network that carries most intercontinental phone calls and television transmissions. Clubs represent a low-cost institutional arrangement for collective provision that can be member owned and operated or government provided.

\footnotetext{
${ }^{3}$ SIEPAC is a power grid involving Costa Rica, El Salvador, Guatemala, Honduras, Nicaragua, and Panama (Arce, 2004).
}

黛 Springer 


\subsection{Joint Products}

Joint products arise when an activity yields two or more outputs that may vary in their degree of publicness. Jointly produced outputs may be purely public, private, a club good, or something else. Actions to preserve a rain forest not only yield local public goods (e.g., a watershed, ecotourism, and localized climate influences) but also GPGs (e.g., biodiversity and sequestration of carbon). Eliminating a local insurgency not only provides RPGs in the form of fewer refugees and a reduced spread of diseases, but also a TPG from a smaller likelihood of a contagious conflict. Regional peacekeeping may offer similar joint products. Foreign aid is also associated with joint products. Conditionality may provide donor-specific private benefits, while poverty reduction in the recipient country can create an altruistic GPG as the global community benefits from welfare improvements in poor countries.

For joint products, the prognosis for effective collective action depends on the ratio of excludable benefits-e.g., contributor-specific and club good benefits- to total benefits. As this ratio approaches one, the share of excludable benefits grow in importance, thereby enabling markets and clubs to efficiently allocate resources to the activity's provision. If, instead, this ratio approaches zero so that all jointly produced benefits are nonexcludable, then underprovision and/or overutilization will result and intervention is needed. Since this ratio can assume any value between zero and one, many scenarios are possible. Institutional design can endogenize this ratio so that collective action can be fostered by augmenting country-specific and excludable benefits to provide incentives to potential supporters. For example, tying voting privileges to a donor country's International Monetary Fund (IMF) quota is a way to motivate greater support.

\subsection{Third Property of Publicness: Aggregation Technology}

The third property of publicness is the aggregation technology, which indicates how individual contributions to the public good contribute to the overall quantity of the public good available for consumption. This aggregator property influences the incentives that potential contributors possess and, hence, affects the prognosis of supply. Each of the subclasses of public goods introduced above can be further subdivided by the aggregation technology to gain a better perspective on contributor incentives (Sandler, 2003).

Traditionally, the only aggregator assumed was summation where the overall level of the public good equals the sum of the agents' contributions to the good. In cleansing a local ecosystem, the level of cleanup equals the sum of the pollutants removed, where each agent's removal efforts adds in a cumulative fashion. The measure of the number of diseased patients treated equals their sum. In addition, the quantity of regional parks and/or rain forest preserved corresponds to the sum of hectares protected. A distinguishing feature of summation is that every contributor's efforts are perfectly substitutable for those of others; one nation's unit of provision has the same impact on the total level of the public good as a unit supplied by anyone else. Without exclusion, free-rider incentives are then a prime concern because another nation's provision limits the need for the nation to contribute. When summation is associated with the two classic properties of pure publicness, an 
RPG has little likelihood of supply unless some outside party, such as an international organization, takes over.

A less extreme form of summation is where the overall level of the public good equals a weighted sum of agents' contributions. Thus, actions to curb the spread of an infectious disease may differentially depend on individual efforts where those taken to protect the most susceptible population have a greater payoff. When reducing sulfur deposits falling on a country, the influence of cutbacks abroad depends on wind patterns, the sites of emission sources, and the pollutants' airborne time. Cutbacks in an upwind country can have a greater impact than the same cutback in another country, not in the pathway of the prevailing winds. With weighted-sum technology, provision is no longer a perfect substitute and so incentives to act may differ among nations. For example, a country that dumps more of its sulfur on itself or else receives relatively large amounts from other countries has strong incentives to sign treaties that mandate cutbacks.

If a weakest-link aggregator applies, then the smallest contribution fixes the public good's aggregate level. The effectiveness of actions to maintain the integrity of a network or to monitor a regional disease outbreak hinges on the least adequate measures. A network will fail at its weakest point; the ability to stem an outbreak depends on the least adequate intelligence. With a weakest-link public good, matching behavior is anticipated because there is no gain from providing beyond the smallest contribution level. Contributions above this level utilize scarce resources but do not augment the overall amount of the public good. If all nations in a region have similar means and tastes, then nations are motivated to attain an acceptable standard of RPG provision. Free-riding incentives are eliminated; contributing nothing means that the effective level of the good is naught regardless of the contributions of others. With diverse means or income, the poorer nations possess insufficient capacity to provide a level of the weakestlink public good acceptable to wealthier nations. The latter are, however, motivated to contribute in-kind to the RPG to achieve an acceptable level (Vicary and Sandler, 2002). If all nations in a region are poor, then rich nations in other regions are motivated to give, provided that the public good has spillover benefits outside of the region. Thus, even weakest-link RPGs may present an allocation concern for poor regions if the RPGs offer little to countries outside of the region.

A less demanding form of a weakest-link RPG is a weaker-link RPG, for which the smallest contribution has the greatest impact on the good's aggregate level, followed by the second smallest contribution, and so on. Applying prophylactic measures against a regional disease is a weaker-link RPG since action that exceeds the minimum level can achieve additional gains, though these diminish at the margin as the contribution rises (Arce and Sandler, 2001; Sander, 1998). With weaker link, there is less incentive for matching behavior because suppliers can somewhat make up for inadequate provision of others; thus, the necessity to bolster capacity is attenuated. There is, however, a need to coordinate which nation does more to make up for the shortfall of others.

Another aggregator is threshold where the benefits of an RPG are only experienced once the cumulative quantity of the good surpasses a certain level. For example, regional flood control may only be effective after a sufficient level of protective measures is deployed to handle an anticipated flood. Similarly, forest fire suppression may have to exceed some threshold, depending on the conflagration, 
before any containment can be achieved. A threshold technology also characterizes regional peacekeeping and crisis-management squads, where insufficient provision is a recipe for disaster. When a threshold applies, there is a need to pool efforts. Leadership by one or more nations can help meet the threshold. The threshold aggregator limits the incentive to free ride until the threshold is attained.

A sixth aggregator is best shot where the largest contribution solely determines the good's overall level-lesser action is redundant. Best-shot RPGs include curing a region-specific disease, uncovering geoclimatic-specific research, building a regional satellite-launch facility, and launching hurricane-tracking satellites. Bestshot RPGs requires coordination so that effort is not wasted through duplication. Coordination problems may be tricky in the presence of more than one best-shot candidate. In many developing regions, this is not a concern because there is, at most, a single country with the requisite capacity. A greater worry is that some regions may be devoid of any nation with the necessary capability. In these cases, the nations will either have to pool their efforts to provide the best-shot RPG or else seek assistance from outside of the region. With development trends, China and India will gain capacity to assume a leadership role in Asia, while Brazil will be able to do so for South America.

Better shot is a less extreme form of best shot, where the greatest contribution has the largest influence on the RPG's provision amount, followed by the second largest contribution, and so on. Examples of better-shot RPGs include discovering effective vaccines, cleaning up an oil spill, providing biohazard facilities, and biospecting. In these instances, a second-best effort can still provide some benefits despite the presence of a greater effort. For example, a less effective vaccine may benefit those who cannot tolerate the more effective one. With better-shot RPGs, there is less need to coordinate and/or concentrate effort.

\subsection{Implications of Publicness Properties}

In Table 1, a typology for RPGs is displayed along with examples of each of the 28 categories displayed. A number of implications are essential for understanding the provision problem posed by RPGs, associated with the three properties of publicness. First, nonrivalry and nonexcludability of benefits are insufficient to gauge the prognosis for RPG provision. This is aptly illustrated by a weakest-link purely public good, where the classic public good properties suggest a bad provision prognosis. When, however, these properties are coupled with weakest link, the supply outlook is promising if the agents have similar tastes and income. This follows because free riding is no longer an option. Second, club RPGs can be efficiently provided by the members when tolls account for crowding. This efficient outcome holds for all aggregators except weakest link, for which externalities from undersupply or poor maintenance may not be fully internalized. Third, joint products' RPGs can be adequately supplied whenever there is a large share of excludable benefits. This share can be raised through institutional innovation that engineer contributor-specific benefits (Sandler, 2004: 90-97). Fourth, a weightedsum technology may support RPG supply whenever there is sufficient weight on the country's own efforts relative to other countries' efforts. Fifth, weakest-link type aggregators highlight the importance of capacity, while best-shot type of aggregators (including threshold) underscore the importance of coordination and/or pooling of 


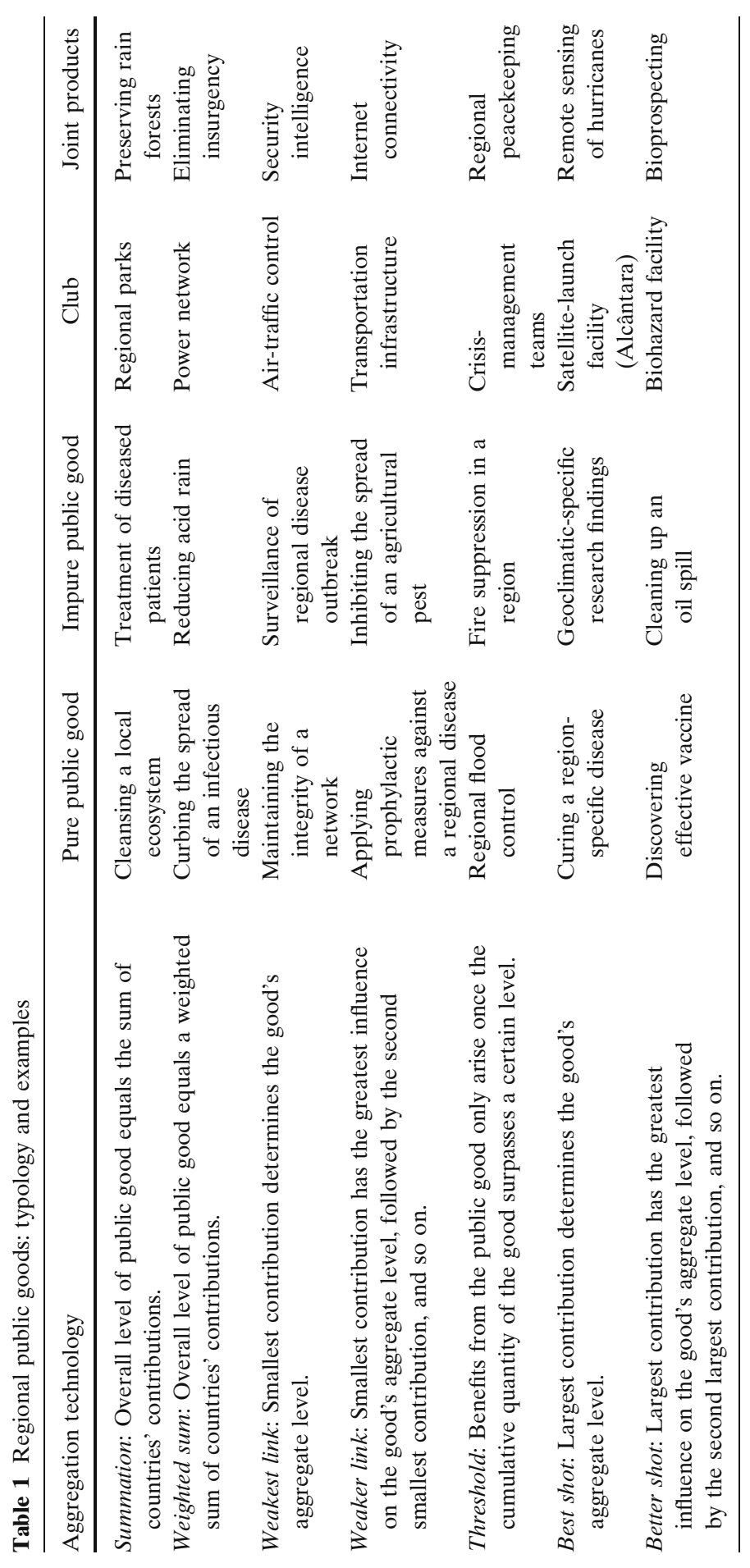


effort. For both sets of aggregators, less-developed regions may have to look beyond their territory to rich donors, charitable foundations, global institutions, and others for help to bolster capacity or to surpass required thresholds. In some weakest-link situations, the added capacity may come in the form of an in-kind transfer intended to attain an acceptable provision standard. Sixth, the primary concern arises when these weakest-link and best-shot RPGs hold little interest for rich countries in other regions. In these cases, there may be little choice but to rely on global and regional institutions, or new participants.

\section{RPGs Versus GPGs}

In many ways, RPGs are in a unique position compared with NPGs and GPGs. An understanding of this uniqueness is essential to prescribe the proper intervention and the appropriate international organization, if any, to assist. By benefiting residents, NPGs provide adequate incentives for the recipient nation to assume a loan to underwrite the good-sufficient ownership exists. There is no free-riding issue among nations since, by their nature, these goods' benefits do not spill over to other nations. By supplying the social overhead capital required for development, NPGs play a complementary role in setting the stage for developing countries to take advantage of TPGs (World Bank, 2001). GPGs and TPGs offer spillover benefits for donor nations outside of the recipient region. This last realization suggests that there are considerations that inhibit RPG provision when compared with GPGs. Many researchers have solely emphasized the supportive factors that favor RPG provision over GPGs. ${ }^{4}$

RPGs involve fewer nations than GPGs which can favor collective action at the regional level. By limiting uncertainty, spatial and cultural propinquity foster RPG provision compared with GPGs where all cultures are present. In recent years, the rise in regionalism has given birth to regional trading blocs as well as a greater regional identity (Mansfield and Milner, 1999). These trading blocs supply some of the requisite infrastructure to facilitate RPG provision-e.g., trading blocs can offer collateral for loans, supply RPGs, or coordinate supply efforts. The European Union (EU) has been instrumental in coordinating RPG provision in Europe, where the EU spearheaded action to curb acid rain and other regional pollutants. In addition, many RPGs possess some favorable publicness properties that foster provision. For example, the underlying aggregation technology for curbing surface ozone is weighted sum in which nations experience the greatest share of their own pollutants, thereby motivating action. A final favorable influence is that of past and ongoing interactions among regional participants, which mean that defecting from an agreement can result in subsequent punishment. Unlike the global level, nations are in constant contact at the regional level so that short-run gains from reneging on an agreement may not justify the long-term retribution.

Other factors inhibit RPG provision relative to GPGs. One RPG concern is the possible absence of a leader nation to coordinate action and to publicize the region's needs. With development, leader nations may eventually emerge-e.g., Nigeria in

\footnotetext{
${ }^{4}$ Researchers who soley focus on supportive factors for RPG include Barrett (2002) and Ferroni and Mody (2002).
} 
West Africa or China in Asia. In some cases, regional rivalries have worked against a united stance on RPG needs. These rivalries have been fueled by neighborhood civil wars, whose economic consequences have adversely affected neighboring nations (Murdoch and Sandler, 2004). Since the late 1990s, civil wars have plagued many developed countries, thereby hampering growth and the support of RPGs (Collier et al., 2003). These civil wars not only destroy social overhead capital in war-torn countries but also induce peaceful countries to erect expensive firewalls to limit harmful consequences. Such action curbs RPG supply. Compared with GPGs, RPGs may experience greater uncertainty owing to insufficient information-e.g., many developing regions do not monitor emissions to track sources and recipients.

The special problems of RPGs also arise from regional institutional considerations. There has been a lack of a global culture to support regional development banks, which has limited their capacity to support RPGs. Donors have traditionally turned to the global institutions to channel some of their support to developing countries and their public good needs. This culture is changing as regionalism, a localized form of globalization, takes hold. If this transformation is to make a difference, then regional development banks must also change their practices. One study shows that these banks gave tiny percentages of their foreign assistance in the form of TPGs (which includes RPGs) during 1996-98: 4.18\%, African Development Fund; 6.86\%, Asian Development Bank; and 1.97\%, Inter-American Development Bank (te Velde et al., 2002: 126). In contrast, these institutions gave large aid percentages to NPGs during 1996-98: 34.73\%, African Development Fund; 47.34\%, Asian Development Bank; and 69.15\%, Inter-American Development Bank (te Velde et al., 2002: 127). Even more worrying is that the percentage of aid in support of TPGs has fallen since 1980-this is not encouraging for these institutions to bolster RPG support!

In a subsequent study, Mascarenhas and Sandler (2005) establish that the regional development banks did not tailor their loan-grant mix to reflect the degree of publicness of supported activities. Loans are more appropriate when recipientspecific benefits dominate, while grants are appropriate when regionwide benefits dominate. Essentially, regional development banks applied a fixed percentage for the various functional areas-e.g., the environment, governance, and knowledgeunlike bilateral donors and global institutions that tailored this mix to publicness considerations. This is additional evidence that these banks must adjust their procedures if they are to warrant enhanced funding. These banks can perform an essential role to address another inhibiting factor of RPG provision-i.e., the absence of a clear entity to obtain loans, provide collateral, and promote a regional agenda. This role must be assumed by either a dominant nation in the region, if one exists, or a regional trading bloc. The regional development banks can then work together with one or both of these entities to fund RPGs.

Table 2 provides a summary of the factors that favor and inhibit support of RPGs, compared with their GPG counterparts. What must be emphasized is that RPGs face many impediments, despite their smaller set of nations, that do not confront GPGs. For RPGs, many difficulties stem from the lack of the necessary infrastructure and inexperience in supporting regionwide needs. Merely giving more money to regional development banks will not fix the problem unless explicit action is taken to earmark funds to RPGs. Measures are also needed to prepare regional trading blocs and organizations to represent the region's interest in supplying RPGs. 
Table 2 Are RPGs harder or easier to provide than GPGs?

Factors promoting RPGs over GPGs

RPGs have fewer participants than GPGs.

Spatial and cultural propinquity limit uncertainty with respect to RPG provision.

New regionalism and the rise of trading blocs can provide the necessary infrastructure to facilitate regional provision.

Favorable characteristics of publicness-e.g., joint products, weighted sum, and excludable benefits.

Past and ongoing interactions among regional participants.

Factors inhibiting RPGs compared with GPGs

Absence of donor spillovers owing to regional specificity of benefits.

Absence, at times, of a leader nation within the region.

Regional rivalries, fueled by local conflicts.

Greater uncertainty owing to lack of information concerning some RPGs.

Lack of global culture in supporting regional development banks, which has resulted in insufficient capacity.

Poor past behavior by some regional development banks-i.e., not tailoring the loan-grant mix to public good considerations and not supporting RPGs.

No clear entity to obtain loans, provide collateral, and promote a regional agenda.

\section{Subsidiarity and RPGs}

Subsidiarity indicates that the decision-making jurisdiction should coincide with a public good's region of spillovers. Strict adherence to subsidiarity dictates that global institutions supply GPGs and TPGs, regional institutions provide RPGs, and nations support NPGs. Subsidiarity is modeled after the notion of fiscal equivalence (Olson, 1969). When the spillover range of the public good extends beyond the political jurisdiction, decision makers often fail to account for all who benefit and, consequently, the public good is undersupplied. If, instead, the political jurisdiction exceeds the public good's spillover range, taxes are then imposed on some people (nations) that do not benefit, thus resulting in an oversupply of the good.

In an ideal world, regional institutions will coordinate its member nations to supply RPGs. When regions are too poor to support sufficient RPGs, regional development banks and other donors can underwrite these regional institutions to achieve subsidiarity. By matching political and economic domains, subsidiarity fosters efficiency because the RPG's marginal benefit (summed over regional recipients) is equated to its marginal cost. Another benefit of subsidiarity is that it limits transaction costs by reducing the number of participants to just those with a stake in the decision. As these participants interact over time, incentives are fostered to abide by agreements, thereby reducing enforcement cost. Repeated interactions also lessen asymmetric information and its associated transaction costs. Localized regional benefits increase the evolution of regional institutions from shared culture, norms, concerns, experiences, and values (North, 1990). As in a fiscal federal system, region-based provision may also lead to best-practice innovations that can be copied by other regional institutions. Centralized provision at the supranational level inhibits such innovations. Greater reliance on regional institutions avoids "mission creep" as global institutions have assumed an ever-wider array of activities. Mission creep can impair the performance of these global institutions as organizational communication lines become complex. 
There are also considerations that detract from applying subsidiarity. Economies of scale can justify having an RPG provided by an institution whose political domain exceeds that of the requisite region whenever the reduced unit cost offsets any lost efficiency. In a global institution, economies of scale may arise from fixed costs that can be spread over serving the needs of multiple regions. For example, peacekeeping would be more expensive per deployment than UN peacekeeping if each region maintains its own peacekeeping forces and equipment. Another factor that limits the application of subsidiarity are economies of scope associated with providing two or more TPGs in the same institution. Economies of scope come from unit cost savings as common inputs (e.g., a communication network or administrative staff) are used to supply these TPGs. Because the spillover range from two or more TPGs is unlikely to coincide, the common provision of multiple TPGs by a single institution is not expected to satisfy subsidiarity. As the number of jointly supplied public goods increases, the anticipated violation of subsidiarity strengthens.

Another obstacle to subsidiarity may involve the absence of the requisite regional institution or jurisdiction. For example, the available regional institution may not entirely match the RPG's spillover range. In the case of river blindness (Onchocerciasis), the disease affected three different regions-Latin America, Africa, and the Arabian Peninsula. Either a new jurisdiction had to be cobbled together by linking three separate regions or else one region has to take up the cause for the other regions. A public-private partnership (i.e., Onchocerciasis Control Partnership) between Merck, the World Health Organization (WHO), host countries to the disease, and donors formed to address river blindness, in which Merck contributed Ivermectin to control the disease and the other partners assisted in the drug's distribution. For some best-shot, better-shot, and threshold RPGs, the required effort may necessitate pooling resources beyond the jurisdiction identified by subsidiarity. This is relevant for actions against communicable diseases in those regions that lack sufficient research facilities and medical personnel. For the search of an HIV/AIDS vaccine, the requisite research infrastructure only exists in a few countries outside the most threatened regions.

Table 3 summarizes supporting and detracting influences on the application of the subsidiarity principle for the provision of RPGs. The new regionalism should over time result in more capable regional institutions, as it has in Europe. As regional institutions are strengthened, subsidiarity can be applied to a greater extent; however, subsidiarity is not always desirable. When scale and scope economies are significant or pooled efforts are required owing to best-shot considerations, either global institutions must step in or else regional institutions must coordinate efforts across regions. There is an essential role that diverse institutions and innovative institutional forms must assume to further regional cooperation when subsidiarity fails as a guiding principle.

\section{Institutions and RPGs}

In practice, the likely failure of subsidiarity in developing parts of the world is being addressed by myriad participants that foster RPG and GPG provision. At the regional level, regional development banks can provide funding. Regional trade pacts serve two purposes: increase interregional trade and coordinate efforts to provide

Springer 
Table 3 Supporting and detracting influences on regional subsidiarity

Supporting factors for regional subsidiarity

Fosters efficiency by equating the good's marginal benefits (summed over regional recipients) to its marginal costs.

Limits transaction costs by reducing the number of participants, augmenting repeated interactions, and curtailing asymmetric information.

Supports the evolution of institutions from shared culture, norms, concerns, experiences, and values.

Bolsters interregional innovations.

Avoids "mission creep" of multilateral institutions.

Detracting factors for regional subsidiarity

Economies of scale from reduced unit costs favor allocation by a larger jurisdiction.

Economies of scope from reduced unit costs encourage providing two or more regional public goods in the same jurisdiction.

The requisite regional institution may not exist nor possess sufficient capacity.

Certain aggregation technologies favor jurisdictions beyond those identified by regional subsidiarity.

RPGs. When the pacts do not act to support RPGs, new regional organizationse.g., SIEPAC in Central America for power and the Regional Fund for Agricultural Technology (FONTAGRO) in Latin American for research-can be created.

Global organizations are appropriate when subsidiarity has too many roadblocks. Such institutions can pool funds and coordinate responses for best-shot, threshold, and summation RPGs, or provide capacity for weakest-link RPGs. Many of these organizations are geared to the three focus areas-e.g., World Health Organization (WHO) and UN Development Program (UNDP) for communicable diseases, United Nations for peace and security, and World Bank for knowledgediscussed in the next section. When RPGs possess interregional spillovers and does not fit into a single region, networks-e.g., Global Environment Facility (GEP) and Consultative Group for International Agricultural Research (CGIAR)—offer a novel institutional alternative. Networks can pool effort for best-shot RPGs and bolster capacity for weakest-link RPGs. A network can limit transaction costs by keeping interregional links loose when little more than information and best practice need sharing; thus, linked organizations can operate quite autonomously. GEP and CGIAR can serve as role models for addressing health concerns and knowledge creation.

Another institutional innovation to facilitate RPG provision is a public-private partnership among diverse participants that may include firms, regional organizations, global institutions, and other entities. Partnerships draw on the comparative advantage of their members and have been popular in providing health public goods. Given their heterogeneous composition, partnerships are especially attuned to addressing problems that cannot be pigeonholed into a single region, such as river blindness, malaria, and HIV/AIDS.

Other institutions-charitable foundations, NGOs, and nation-based organizations-bolster efforts to supply RPGs. Charitable foundations and NGOs provide inflows of new funds for health issues, the commons, knowledge, and other concerns that do not reduce standard funding sources. For communicable diseases, charitable foundations and nation-based organizations (e.g., the Centers for Disease 
Control, National Institutes of Health, and Pasteur Institute) focus resources on bestshot RPGs or provided capacity for weakest-link RPGs. Nation-based organizations are particularly interested in diseases that may threaten interests at home. NGOs have wider interests and champion many global and regional concerns including refugees (e.g., Red Cross and Medecins Sans Frontièrs) and environmental issues (e.g., Greenpeace).

Table 4 summarizes eight categories of institutions and how they promote RPGs.

\section{Three Essential RPG Sectors}

Essential features of three important RPG sectors are now examined. Some sectors have much better prognosis than others; efforts must be directed at those where incentives are unsupportive for regional or global collective action. These sectors differ according to public good properties, institutional capability, and provision prognosis.

\subsection{Peace and Security}

Since the late 1960s the global incidence of civil wars increased until 1988, at which time it fell somewhat before leveling off at an elevated high level. Conflict-torn countries are associated with refugees, trade disruption, poverty, low economic growth, diseases (e.g., HIV/AIDS and malaria), and financial instability. In terms of the latter, civil wars lead on average to a flight of ten percent of a country's capital (Collier et al., 2003: 15). Reducing intrastate and interstate conflict is one activity that can simultaneously contribute to many RPG issue areas. Conflict may not only spread from one country to the next, but may also generate a wide range of negative externalities, whose reduction represents RPGs. In a recent study, Murdoch and Sandler (2004) show that regional wars can reduce a nearby peaceful country's growth by about one half of a percentage point; thus, four regional conflicts will wipe out most countries' growth in the region.

Security concerns also arise from terrorism. Although transnational terrorism has fallen since the early 1990s, each incident is now more likely to result in casualties (Sandler and Enders, 2004; Enders and Sandler, 2006). The four hijackings on 11 September, 2001, (hereafter 9/11) underscore that a well-planned attack can have significant consequences in lives and economic losses. Transnational terrorism is associated with a "transference externality" in which increased protection taken in one location transfers the attack to less secure venues in other countries or regions. This suggests that security against transnational terrorism is a GPG necessitating global coordination. For example, attacks against Americans in the Middle East and elsewhere motivate U.S. willingness to bolster defenses abroad if requested. Since the rise of fundamentalist terrorism after 1979, there has been a shift of transnational terrorism to the Middle East and Asia (see Enders and Sandler, 2005). This shift is quite dramatic after $9 / 11$ and the subsequent upgrades to U.S. homeland security.

Other security risks arise from the proliferation of weapons of mass destruction (WMDs) - e.g., Pakistan and India-and organized crime. WMDs pose a global problem since once available in a region, these weapons can get into the wrong 
Table 4 Role of institutions in fostering RPGs

Institutional

Purposes/function

categories

Regional Development Banks

Regional Trade Pact

Global Multilaterals: World Bank, UNDP, WHO, WTO

Networks: Global Environment Facility (GEP), Consultative Group for International Agricultural Research (CGIAR)

Partnerships: Global Fund, Onchocerciasis Control Partnership, Medicines for Malaria Venture

Charitable Foundations: Wellcome Trust, Gates Foundation

Nongovernmental Organizations: CARE, Red Cross, Medecins Sans Frontièrs, Greenpeace

Nation-Based Organizations:

Centers for Disease

Control (CDC), National

Institutes of Health (NIH),

Pasteur Institute
Provide funding for RPGs. This funding can be in the form of loans and grants depending on the degree of publicness of the supported activity. Grants are more appropriate when public goods provide regionwide or interregional spillovers. Coordinate action to promote regionwide financial stability.

Promotes trade within the region. These pacts can coordinate efforts to provide RPGs. In some instances, pacts can provide collateral for RPG loans.

Pool funds for best-shot, threshold, and summation public goods and bolster capacity for weakest-link public goods. Can assist for all RPG areas with some global institutions specializing in a specific area-e.g., WHO in communicable diseases. Global institutions can channel funds to regional institutions to augment their financial capacity.

Link together interests within and among regions for providing RPGs and TPGs. For example, GEF addresses regional and global commons issues, while CGIAR focuses on knowledge. Other networks are particularly suited for supplying TPGs that have interregional spillovers. They are also useful for weakest-link and weaker-link TPGs.

Draw on the comparative advantage of diverse participants. Many partnerships concern diseases, but other partnerships can form to address other key areas.

Provide inflow of new funds for health issues. Also fosters knowledge. Bolster capacity for weakest-link RPGs and pool resources for best-shot and threshold RPGs. Support communicable diseases where developed countries may have limited interests. Limit crowding out by bringing in new donors.

Address specific public goods-e.g., disaster relief, environmental needs, immunization, and refugee needs. Champion some global and regional environmental concerns.

Supply health-related public goods in terms of outbreak surveillance, data collection, disease isolation, and vaccine development. These organizations are interested in infectious diseases that may pose a threat to the institution's host country. Except for the US Environmental Protection Agency and the global commons, similar nation-based institutions have not developed for other key sectors. 
hands-e.g., the transfer of nuclear technologies to other countries by Pakistan's top nuclear scientist. Globalization involves both legal and illegal exchanges, so that organized crime in one region has consequences in other regions. In Afghanistan, the defeat of the Taliban resulted in a weaker government that has been unable to control poppy cultivation-an unintended global public bad resulting from antiterrorism action in the wake of 9/11. Thus, security actions in one region cannot necessarily be isolated from consequences in other regions.

Proactive measures against transnational terrorism, WMD proliferation, and organized crime represent a best-shot public good. Even if the action is regionspecific, the associated threat is mobile and so such measures constitute GPGs rather than RPGs. In contrast, defensive actions to forestall the spread of terrorism, weapon proliferation, or crime is a weakest-link public good. Defensive measures also have global implications owing to transference of terrorists or criminals to safe havens and their attacks to soft targets. Most regions do not possess the military prowess to act proactively; hence, regions generally resort to venue-shifting defensive actions. At some point, the world must realize that much of today's security threats must be addressed on a worldwide scale by global institutions and powerful alliances when there is a sufficient consensus to legitimize a proactive response. Shoring up weakest links often creates new ones as terrorists or criminals identify new targets of opportunity. Furthermore, actions to shore up weakest links offer free-riding incentives.

A regional approach to transnational terrorism or organized crime is not going to end these threats as terrorists and criminals move their base of operations. The USled attacks against al-Qaida in Afghanistan after 12 October, 2001, reduced transnational terrorism in the short-term, but such attacks are now increasing (Enders and Sandler, 2005, 2006). For WMD proliferation, a nation or alliance must come forward with the power to eliminate a proven WMD. The "best shooter" needs a mandate from the global community to act. In many regions, there is currently insufficient capacity to confront a powerful nation determined to acquire WMDs. Some form of global coordination is required.

Unlike the other security threats, civil wars can, at times, be addressed at the regional level. In the case of East Timor, Australia took a lead role in peacekeeping. Reliance on regional entities for peacekeeping, however, presents some concerns. First, the peacekeeping country must bring peace without pursuing its own agenda and gain. Second, the region must contain a capable peacekeeping country or a sufficiently strong alliance to bring peace. Third, regional peacekeeping must be economically sensible compared with such action by the United Nations or NATO. Putting too much reliance on regional alliances for localized peacekeeping can result in wasteful duplication of forces, which can increase the unit cost of peacekeeping. Since the end of the Cold War, NATO has assumed peacekeeping missions in Europe, while the United Nations has taken on these missions in most other places. This distribution of effort has worked even though there is no formal agreement. A more formal arrangement will be difficult to frame because NATO's Articles mandate that any military deployment must be unanimously approved by its allies.

\subsection{Knowledge}

Knowledge is the quintessential best-shot or better-shot public good, where breakthroughs come from concentrating effort and building up research centers of 照 Springer 
excellence. Best-shot and better-shot aggregation also means that a coordination of action is required; thus, research for region-specific knowledge needs efforts to be orchestrated and funded by a global or regional institution. Once discovered, knowledge also represents an intergenerational public good that provides nonrival benefits to the current and future generations. Because benefits conferred to future generations are unlikely to be fully taken into account by the provider, knowledge will be undersupplied in an intergenerational sense even under the best of circumstances. To provide incentives for knowledge production, governments issue patents that confer monopoly rights for a set period to the creator. These patents imply an interesting tradeoff: restricted use in the near-term in return for a larger number of discoveries. The optimal patent period must balance welfare losses from restricting short-run consumption with the long-term gain of more discoveries.

Knowledge presents some interesting RPG issues. First, there is a marked tendency for rich nations to pursue knowledge that primarily furthers their interests. In health, this is known as the 90/10 gap in which less than $10 \%$ of U.S. annual spending on health-related research and development addresses the health concerns of $90 \%$ of the planet's population (WHO, 2002: 23). Similar gaps hold for all forms of knowledge creation. Second, knowledge reflects increasing returns in production where a substantial effort must be attained before payoffs are realized. Third, many developing regions must acquire complementary NPGs to take advantage of the knowledge created elsewhere-e.g., Sub-Saharan Africa and Central America. Fourth, many regions have limited capacity to conduct research on the requisite scale. Fifth, owing to specific diseases, geoclimatic conditions, and other regionspecific circumstances, the RPG needs of some regions provide little or no spillover benefits to other regions, so that these regions must produce their own knowledge or get funding and other assistance from global institutions, charitable foundations, networks, partnership, or NGOs.

To address these unique region-based problems, a planned sequence of actions is required. The global community must first provide the complementary NPGs, including improving educational attainment, for poor regions. Networks can then be relied upon to pool resources and expertise across regions to achieve best-shot breakthroughs and surpass required thresholds. Regional development banks and regional trade pacts can provide a source of funding; shortfalls can be made up by global institutions (e.g., the Global Fund is financing vaccines and other healthrelated knowledge searches for malaria and HIV/AIDS). Region-based research institutions are essential if region-specific needs are not to be ignored. Interregional cooperation can foster scale economies regarding similar research questions.

\subsection{Communicable Diseases}

Regional communicable diseases may or may not present a concern to the global community. In those cases, such as SARS or bird flu, where a worldwide epidemic may occur, actions to monitor and isolate a regional outbreak constitute GPGs. Obviously, rich nations and their institutions (e.g., CDC, NIH) are motivated to offer help to raise capacity to address such diseases. For those regional diseasescommunicable or otherwise-where rich nations are not in harm's way, there is less interest to augment a region's healthcare ability. Curing, monitoring, and/or ameliorating a region-specific disease is an RPG with little apparent spillover to 
the global community. In fact, Kremer and Leino (2004) view most public goods associated with communicable diseases as NPGs and RPGs. This viewpoint, however, misses some indirect links and subtleties. Nation-specific and regionspecific infections weaken a host population and make it more vulnerable to other communicable diseases that can travel to other venues. Plane travel facilitates rapid dissemination of acquired diseases. Similarly, an inadequate health infrastructure makes a population more susceptible to diseases that can spread worldwide. The ability to eradicate a disease through inoculation hinges on achieving sufficient immunity. Costly vaccinations must be administered worldwide until herd immunity is attained; hence, rich countries experience an externality unless a disease is completely eradicated. Inadequate healthcare responses in any region can have global spillovers.

Communicable diseases are associated with a host of public goods: educating people about transmission, finding a cure, limiting the spread, eradicating a disease, isolating a bacterium or virus, developing a vaccine, establishing best treatment regime, and others. Many of these public goods are either of a weakest-link or bestshot variety. For weakest link RPGs, building capacity is the key because the least effort by a nation in the region determines the regionwide public good level achieved. Thus, an inadequate prophylactic by one nation permits the disease to spread and jeopardize the whole region. For poor regions, this enhanced capacity must come for bilateral donors, global institutions, or the regional development banks. If the region does not possess the proper infrastructure to use funds to provide the weakest-link RPG, then the aid must be in-kind with the donor supplying the good directly.

At the regional level there is also a need for assistance to provide disease-related best-shot and better-shot public goods. The need is particularly acute for regionspecific communicable diseases that present little concern to rich countries. As with weakest-link RPGs, capacity is an issue that must be supplied by others working either alone or in partnerships. In recent years, foreign assistance to the health sector has increased. ${ }^{5}$

Another concern is that developed and developing countries have different needs with respect to diseases. For HIV/AIDS, developed countries benefit from the development of more effective treatment regimes for those infected. Developing countries gain more from a vaccine that prevents the disease owing to the high rate of new infections and the limited funds for costly treatment regimes. Rich countries are more interested in noncommunicable diseases, such as heart disease and cancer, than developing countries, and thus direct more of their research budget to ailments that pose less risk to the latter, whose population's life expectancy is shorter. Pharmaceutical companies heighten this asymmetry by developing drugs for lucrative markets with an emphasis on noncommunicable disease. This difference in orientation means that disease-related discoveries and treatments in rich countries have fewer spillovers to developing countries. Thus, best-shot health-related public goods are not going to come very frequently from rich countries. This emphasizes the need for assistance that account for the

\footnotetext{
${ }^{5}$ See the figures in Mascarenhas and Sandler (2005) and te Velde et al. (2002). This increase has drawn funds away from other sectors such as the environment.
}

照) Springer 
special health needs of the developing regions-e.g., funds for prevention of HIV/ AIDS, tuberculosis, and malaria.

Many public goods associated with communicable diseases provide intergenerational spillovers of benefits. Once a disease is cured or a virus is isolated, benefits are conferred on the present and future generations. These intergenerational benefits mean that undersupply will be significant as both interregional and intergenerational spillovers are ignored when allocation decisions are made.

\section{Conclusions and Recommendations}

A key conclusion is that RPGs pose many collective action difficulties, not associated with GPGs. Nations have proper incentives to finance NPGs due to direct gains, while rich nations possess incentives to underwrite GPGs owing to spillover benefits. Neither individual nations nor the world community may have the right motives to fund RPGs. This is consistent with recent empirical work that shows bilateral donors, global institutions, and regional institutions strongly favor NPGs and GPGs over RPGs (Mascarenhas and Sandler, 2005; te Velde et al., 2002). Thus, there is a growing need to focus foreign assistance on creating a more adequate supply of RPGs. To achieve this goal, regional development banks must be given greater financial capacity. These banks must, however, change some practices by supporting more RPGs and tailoring the loan-grant mix to the underlying publicness properties of the supported activity. In order to facilitate loans for RPGs, regional trade pacts and other regional institutions need to represent regional interests and provide collateral for loans.

The publicness considerations of RPGs must assume an enhanced role in tailoring support and institutional design. For example, club RPGs can be privately provided by member-owned collectives that fund the shared good from tolls that account for crowding. Thus, an interregional highway or power grid can be supported in this fashion. Clubs are underutilized at the regional level and should be increased to promote regional infrastructure. The aggregation technology is also an essential consideration. For weakest-link RPGs, a variety of participants are needed to boost capacity so that an acceptable level of these goods is attained regionwide. This added capacity can be provided by global institutitions, partnerships, charitable foundations, and regional institutions. For best-shot and threshold RPGs, these same institutions must step in or pool efforts to supply the good.

The subsidiarity principle should not be blindly followed. As shown, there are offsets to subsidiarity that may require an imperfect match to take advantage of other gains such as scale or scope economies. When TPGs involve interregional spillovers, networks and partnerships of participants from multiple regions are appropriate for supplying the good. Combining interests from multiple regions may also be necessary for some best-shot and threshold RPGs. In such cases, the global institutions can serve an important coordinating function to ensure sufficient investment and the absence of duplication of efforts.

The three focus sectors for public goods have diverse policy recommendations. For most of today's security challenges, a global approach is recommended because proactive measures require a response that most regions cannot, or will not, mount. Moreover, defensive regional responses merely divert the threat to another region. 
As a best-shot RPG, knowledge creation is associated with effort levels that require assistance from global institutions or rich countries. Unless poor regions build up their knowledge infrastructure through outside assistance, their knowledge needs will be increasingly ignored. RPGs associated with communicable diseases adhere to weakest-link and best-shot aggregation technologies. The former requires assistance-funded capacity upgrades, while the latter means that global institutions and rich nations must increase effort. Best-shot actions to cure region-specific communicable diseases will require help from global institutions, charitable foundations, rich nation-based institutions, and public-private partnerships.

Acknowledgments Sandler is the Robert R. and Katheryn A. Dockson Professor of International Relations and Economics. The author has profited from the comments provided by three anonymous reviewers.

\section{References}

Arce, M. D. G. (2004). A selective survey of regional public goods in Latin America. In A. Estevadeordal, B. Frantz, \& T. R. Ngyuyen (Eds.), Regional public goods: From theory to practice (pp. 105-129). Washington, DC: Inter-American Development Bank and Asian Development Bank.

Arce, M. D. G., \& Sandler, T. (2001). Transnational public goods: Strategies and institutions. European Journal of Political Economy, 17, 493-516.

Arce, M. D. G., \& Sandler, T. (2002). Regional public goods: Typologies, provision, financing, and development assistance. Stockholm: Almqvist and Wiksell International for Expert Group on Development Issues, Swedish Ministry for Foreign Affairs.

Barrett, S. A. (2002). Supplying international public goods: How nations can cooperate. In M. Ferroni \& A. Mody (Eds.), International public goods: Incentives, measurement, and financing (pp. 46-79). Boston: Kluwer Academic Publishers.

Collier, P., Elliot, V.K., Hegre, H., Hoeffler, A., Reynal-Querol, M., \& Sambanis, N. (2003). Breaking the conflict trap: Civil war and development policy. Washington, DC: World Bank and Oxford University Press.

Cook, L. D., \& Sachs, J. (1999). Regional public goods in international assistance. In I. Kaul, I. Grunberg \& M. Stern (Eds.), Global public goods: International cooperation in the 21st century (pp. 436-449). Oxford University Press: New York.

Cornes, R., \& Sandler, T. (1996). The theory of externalities, public goods, and club goods, 2nd edition. Cambridge: Cambridge University Press.

Enders, W., \& Sandler, T. (2005). Distribution of transnational terrorism among countries by income classes and geography after 9/11. Los Angeles: School of International Relations, University of Southern California, Unpublished manuscript.

Enders, W., \& Sandler, T. (2006). The political economy of terrorism. Cambridge: Cambridge University Press.

Estevadeordal, A., Frantz, B., \& Nguyen, T. R. (Eds.) (2004). Regional public goods: From theory to practice. Washington, DC: Inter-American Development Bank and Asian Development Bank.

Ferroni, M., \& Mody, A. (Eds.) (2002). International public goods: Incentives, measurement, and financing. Boston: Kluwer Academic Publishers.

Kanbur, R., Sandler, T., \& Morrison, K. (1999). The Future of development assistance: Common pools and international public goods, Policy Essay No. 25. Washington, DC: Overseas Development Council.

Kaul, I., Grunberg, I., \& Stern, M. A. (Eds.) (1999). Global public goods: International cooperation in the 21st century. Oxford University Press, New York.

Kaul, I., Conceição, P., Le Goulven, K., \& Mendoza, R. U. (Eds.) (2003). Providing global public goods: Managing globalization. New York: Oxford University Press.

Kremer, M., \& Leino, J. (2004). Regional public goods and health in Latin America. In A. Estevadeordal, B. Frantz \& T.R. Nguyen (Eds.), Regional public goods: From theory to practice (pp. 227-241). Washington, DC: Inter-American Development Bank and Asian Development Bank. 
Mansfield, E. D., \& Milner, H. V. (1999). The new wave of regionalism. International Organization, $53,589-627$.

Mascarenhas, R., \& Sandler, T. (2005). Donors' mechanisms for financing international and national public goods: Loans or grants? World Economy, 28, 1095-1117.

Murdoch, J. C., \& Sandler, T. (2004). Civil wars and economic growth: Spatial dispersion. American Journal of Political Science, 48, 137-150.

North, D. C. (1990). Institutions, institutional change and economic performance. Cambridge: Cambridge University Press.

Olson, M. (1965). The logic of collective action. Cambridge, MA: Harvard University Press.

Olson, M. (1969). The principle of 'fiscal equivalence': The division of responsibilities among different levels of government. American Economic Review, 59, 479-487.

Raffer, K. (1999). ODA and global public goods: A trend analysis of past and present spending patterns. NY: Office of Development Studies Background Paper, United Nations Development Program.

Sandler, T. (1992). Collective action: Theory and applications. Ann Arbor, MI: University of Michigan Press.

Sandler, T. (1997). Global challenges. Cambridge: Cambridge University Press.

Sandler, T. (1998). Global and regional public goods: A prognosis for collective action. Fiscal Studies, 19, 221-247.

Sandler, T. (2002). Financing international public goods. In M. Ferroni \& A. Mody (Eds.), International public goods: Incentives, measurement, and financing (pp. 81-117). Boston: Kluwer Academic Publishers.

Sandler, T. (2003). Assessing the optimal provision of public goods: In search of the Holy Grail. In I. Kaul, P. Conceição, K. Le Goulven \& R.U. Mendoza (Eds.), Providing global public goods: Managing globalization (pp. 131-151). New York: Oxford University Press.

Sandler, T. (2004). Global collective action. Cambridge: Cambridge University Press.

Sandler, T., \& Enders, W. (2004). An economic perspective on transnational terrorism. European Journal of Political Economy, 20, 301-316.

Stålgren, P. (2000). Regional public goods and the future of international development cooperation: A review of the literature. Working Paper 2000:2, Stockholm, Sweden: Expert Group on Development Issues, Ministry for Foreign Affairs.

te Velde, D. W., Morrissey, O., \& Hewitt, A. (2002). Allocating aid to international public goods. In M. Ferroni \& A. Mody (Eds.), International public goods: Incentives, measurement and financing (pp. 119-156). Boston: Kluwer Academic Publishers.

Vicary, S., \& Sandler, T. (2002). Weakest-link public goods: Giving in-kind or transferring money. European Economic Review, 46, 1501-1520.

World Bank (2001). Global development finance: Building coalitions for effective development finance. Washington, DC: World Bank.

World Health Organization (WHO) (2002). Coordinates 2002: Charting progress against AIDS, TB and malaria. Geneva: WHO. 